\title{
DE CONFLITOS DOMÉSTICOS A MUDANÇAS SISTÊMICAS: A POLÍTICA EXTERNA DE ANGOLA DE 1975 A 2002
}

\author{
FROM DOMESTIC CONFLICTS TO SYSTEMIC CHANGES: ANGOLA'S FOREIGN \\ POLICY THE PUBLIC POLICY FROM 1975 TO 2002
}

\section{Ana Rachel Simões Fortes ${ }^{1}$}

\section{Resumo}

Este artigo tem por objetivo analisar as transformações da política externa angolana de 1975 até 2002. A pesquisa visa compreender como a política externa angolana se desenvolveu frente aos contextos de guerra civil e de mudança no sistema internacional. Para tanto, o marco temporal a ser investigado está dividido em dois momentos. Entre 1975 a 1991, durante a guerra fria, período em que o governo angolano empreendeu sua política externa na busca de estratégias para sua estabilidade doméstica. De 1992 a 2002, pós- guerra fria, marcado por um amplo processo de abertura e de internacionalização de sua economia, que como resultado acarretou em mudanças de estratégia para sua política externa.

Palavras-Chave: Política Externa; Angola; Guerra civil; Guerra Fria; Internacionalização.

\begin{abstract}
This article aims to analyze the transformations of Angolan foreign policy from 1975 to 2002. In this sense, the research aims to understand how the Angolan foreign policy has developed in the context of civil war and change in the international system. To do so, the time frame to be investigated is divided into two moments. Between 1975 and 1991, during the Cold War, a period in which the Angolan government undertook its foreign policy in search of strategies for its domestic stability. From 1992 to 2002, after the cold war, marked by a broad process of opening and internationalization of its economy, which as a result led to changes in strategy for its foreign policy.
\end{abstract}

Keywords: Foreign Policy; Angola; Civil war; Cold War; Internationalization.

\section{INTRODUÇÃO}

A independência política de Angola, em 1975, foi alcançada de forma bastante turbulenta, conquistada na arena de graves conflitos internos, intensa crise social e invasões externas. Perseguida em meio ao recrudescimento da disputa pela hegemonia do sistema internacional, entre Estados Unidos e União Soviética, a libertação angolana foi marcada por uma forte defesa de sua soberania diante das agressões externas sofridas, semeando os primeiros germens do que viria a ser sua política externa.

\footnotetext{
${ }^{1}$ Mestranda em Relações Internacionais pela Pontifícia Universidade Católica de Minas Gerais. Email: anarachelfortes@yahoo.com.br.
} 
A política externa angolana foi resultado de múltiplos fatores, tanto nacionais quanto estrangeiros. Do ponto de vista interno, o país no pós-independência se viu encurralado pelo confronto direto entre o Movimento Popular para Libertação de Angola (MPLA) e a União Nacional para Independência Total de Angola (UNITA), em que cada um, com ideologias e objetivos distintos, buscava o controle do Estado. As divergências de preferências entre esses grupos rivais acarretaram efeitos determinantes na condução da política externa. Por outro lado, no campo externo, as conjunturas internacionais marcadas pela Guerra Fria e pelo fim da mesma também influenciaram diretamente.

À luz dessas questões, por alcançarem a soberania sob condições difíceis e, muitas vezes, violentas, com poucos recursos estratégicos para exercer essa soberania de forma eficaz, muitos países africanos criam e executam suas políticas externas como um instrumento para obter assistência externa a fim de conter problemas internos (MALAQUIAS, 2011). Angola exemplifica esta tendência. Desde que se tornou independente até o fim da sua guerra civil, o país enfrentou graves desafios domésticos e utilizou-se de suas relações exteriores como ferramenta para contenção de sua crise política e econômica. Por isso, analisar os rumos da política externa de Angola perpassa diretamente pelas contribuições desses debates sobre a inter-relação dA variáveis doméstica e sistêmica.

Nesse contexto, este artigo visa analisar como se desenvolveu a política externa de Angola de 1975 até 2002. Ao considerar as variáveis doméstica (guerra civil) e sistêmica (fim da Guerra Fria), buscar-se-á identificar como essas duas variáveis influenciaram na condução de sua política externa. A partir do levantamento documental sobre o tema será possível identificar o comportamento do Estado angolano, frente a pressões tanto no âmbito interno quanto externo. $O$ artigo encontra-se dividido em duas seções, além desta introdução e das considerações finais. A primeira seção versa sobre a política externa angolana durante a Guerra Fria (1975-1991), destacando o processo de construção do Estado e sua busca por legitimação internacional. A segunda seção investiga o período de 1992 e 2002, apontando as mudanças da política externa angolana pós- Guerra Fria, cenário de remodelação da estrutura estatal angolana que em termos econômicos representou a passagem de uma economia centralizada para um amplo processo de internacionalização e abertura econômica.

\section{CONTEXTO PÓS-INDEPENDÊNCIA E A BUSCA PELA LEGITIMAÇÃO INTERNACIONAL: A POLÍTICA EXTERNA DE ANGOLA DE 1975 A 1991}

A independência ${ }^{2}$ angolana foi alcançada no dia 11 de novembro de 1975, com o Acordo de Alvor, que negociou, entre Portugal e Angola, o estabelecimento de um governo de transição,

\footnotetext{
Durante a década de 60 iniciou-se o movimento angolano de independência ${ }^{2}$. Grupos de diferentes vertentes ideológicas almejavam conquistar o poder do país, um amplo projeto de libertação nacional, iniciado no dia 04 de fevereiro de 1961, a fim de bloquear o funcionamento e a atuação do sistema colonial português, tanto na agricultura quanto na indústria, tornou-se a principal pauta para atingir a integração de Angola
} 
composto por membros do MPLA, Frente Nacional de Libertação de Angola ${ }^{3}$ (FNLA) e da UNITA. O processo para a independência foi marcado pela rivalidade desses movimentos nacionalistas, os quais possuíam objetivos, ideologias e propostas distintas tanto no que se refere à condução do processo de independência, como também na constituição do Estado angolano.

Em uma série de manobras, o MPLA conseguiu arrebanhar para si o poder do Estado, adotando um sistema político e econômico socialista. Todavia, o MPLA assumiu o governo em meio a uma conjuntura instável, já que o país mergulhou-se em uma guerra civil e encontrava-se fragmentado em diferentes administrações desses grupos internos rivais (MAIA, 2006).

Do reconhecimento como Estado até o fim da União das Repúblicas Socialistas Soviéticas (URSS) em 1991, o conflito em Angola foi marcado pela influência da Guerra Fria: MPLA defendendo pautas socialistas com o apoio da URSS e a UNITA contando com o auxílio dos Estados Unidos da América ${ }^{4}$ (EUA). "Com grande componente externo, esse conflito, não foi somente dos angolanos, mas sim das potências que procuravam cada vez mais expandir as suas ideologias"5 (SIMIÃO, 2014, p.14).

Uma das características sui generis de Angola é que teve duas declarações de independência: em Luanda, o MPLA proclamou a República Popular de Angola, e no Huambo, a aliança UNITA+FNLA proclamou a República Democrática de Angola (que durou 80 dias, o tempo em que a aliança se manteve). Na sequência destes dois atos, a guerra (anticolonial e civil) iniciada em 1961 prolongou-se até 2002. (PERCISI, 2010, p.8)

O MPLA buscava sua afirmação, uma vez que tinha como principal preocupação, a nível político, promover a unidade em Angola. O seu maior desafio interno era a UNITA, posto que com a guerra constante essa elite governante nunca dispôs de tempo hábil para consolidar o poder do Estado ao longo do território. Mesmo com as dificuldades na construção das capacidades estatais, as ameaças internas e externas puderam ser enfrentadas com amparo externo, inclusive na extração de seus recursos naturais abundantes. É neste contexto que o MPLA, partido que definia os objetivos e tarefas a se realizar pelo Estado, elaborou um programa onde se encontravam identificados os princípios orientadores da política externa angolana pós- independência. Entre as quais pode-se mencionar:

1. Salvaguardar a independência e a integridade territorial; 2. Respeito pelos princípios das Cartas da ONU e da OUA; 3. Reforço da amizade e do

\footnotetext{
${ }^{3}$ Vale ressaltar que este partido foi uma organização com diversas instabilidades e incoerências internas, mesmo atuando no processo de independência angolano. O FNLA iniciou uma gradativa desmobilização que resultou na sua extinção. Desse modo, o conflito passou a ser entre o MPLA e a UNITA.

${ }^{4}$ Estima-se que os EUA além de desrespeitarem o Acordo de Alvor enviaram em 1975, US $\$ 300$ mil em ajuda ao FNLA, mediado pela estação da CIA no Zaire. Como resposta, países do leste europeu enviaram armas e equipamentos para o MPLA, o que foi reforçado pelo apoio soviético, mais próximo à independência. Assessores militares externos, sobretudo cubanos, também serviram de amparo ao movimento. (SILVA, 2015, p. 150)

${ }^{5}$ De acordo com Percisi (2010), de 1975- 1989, as intervenções das grandes potências da Guerra Fria, EUA e URSS, fizeram com que o confronto atingisse maior profundidade. Não só movidas pelo interesse interno no país, devido a grande quantidade de petróleo e de diamantes, as potências travaram também em Angola uma guerra ideológica e deram as assistências financeiras, diplomáticas e de logística necessárias para os seus respectivos movimentos.
} 
desenvolvimento da cooperação com os países socialistas; 4. Solidariedade e apoio aos movimentos de libertação nacional; 5. Coexistência pacífica com os Estados de orientação capitalista; 6 . Relações de boa vizinhança com os países limítrofes. (SIMIÃO, 2014, p. 30)

Apesar de alcançar a independência e ser reconhecida por vários Estados em sua maioria aliados, como a URSS, a sua independência e integridade territorial continuava ameaçada devido a três fatores: O primeiro é a forma como se processou a independência em Angola. Neste país, houve três movimentos de libertação, que possuíam inclinações ideológicas e interesses distintos. Como vimos anteriormente, com a proclamação da independência e com o MPLA no poder, a guerra civil ganhou novos contornos, com a participação de forças estrangeiras em território angolano (SILVA, 2002).

O segundo refere-se a como o Governo assumiu o poder. O MPLA, assim que se consolidou no poder, se afirmou como a única força política do país. Esta prática gerou muitos constrangimentos e só criou mais reservas para o engrandecimento do conflito. E por fim, o terceiro ponte é o jogo das potências mundiais na busca de maiores zonas de influências. "Assim, com base nos dois primeiros fatores, os EUA e a URSS desenvolveram ações no sentido de colocarem neste território um governo que seria favorável as suas orientações". (SIMIÃO, 2014, p.31). Tanto o MPLA quanto a UNITA contavam com suporte na condução de suas políticas, suas ações eram baseadas nas proposições desses financiadores externos.

De acordo com Silva (2015), a política externa é derivada de um processo complexo de construção do Estado em que elites definidoras de política externa ${ }^{6}$ buscam concretizar seus projetos políticos e respondam a pressões domésticas e externas de acordo com as capacidades estatais disponíveis ${ }^{7}$. Destarte, no que concerne ao caso angolano, entre 1975-91, a elite governante tentou minimizar as altas pressões internas com apoio externo dos aliados socialistas.

\begin{abstract}
Os principais desafios da construção do Estado angolano estavam vinculados às capacidades reduzidas herdadas do Estado colonial português (inclusive a destruição causada pela guerra de libertação) e aos desafios imputados pela guerra interna. O projeto de Estado, as prioridades eram estabelecer a ordem interna e fomentar a capacidade econômica. Nas tarefas de reconstrução, Cuba foi fundamental para reduzir o vácuo de poder no serviço público militar, administrativo, médico, de educação e segurança (SILVA, 2015, p. 141).
\end{abstract}

A política externa de Angola originava-se desse amplo processo de construção do Estado fomentado pelas elites do MPLA. "A figura do presidente era relevante para a formulação das diretrizes centrais de política externa, o partido e seus órgãos internos estabeleciam os objetivos políticos e linhas de ação fundamentais" (SILVA, 2015, p.147). Neste período havia três principais

\footnotetext{
${ }^{6}$ Silva (2015) ainda ressalta que os Estados agem frente a ordens sistêmicas estabelecidas (instituições formais e informais que sustentam o regramento de comportamentos e a distribuição de benefícios no sistema) de acordo com os interesses de suas elites e as pressões (ameaças e assimetria de poder) que elas experimentam interna e externamente.

${ }^{7}$ Putnam (1988, p.434), salienta que no nível nacional, grupos domésticos perseguem seus interesses pressionando o governo a adotar políticas favoráveis. Enquanto em nível internacional, os governos nacionais buscam maximizar sua própria capacidade de satisfazer as pressões domésticas, enquanto minimizam as conseqüências adversas externas.
} 
esferas decisórias do MPLA: "1- Congresso do Partido, que reunia uma assembleia de delegados e estabelecia os direcionamentos políticos gerais; 2- Comitê Central, que formulava as políticas específicas, incluindo os departamentos de Política Externa e Defesa; e 3- Bureau Político, órgão eleito do Comitê Central que mantinha o poder de fiscalização sobre a política partidária”. (SILVA, 2015, p 148).

Segundo Silva (2015), as relações entre o partido e o Executivo dominavam o processo decisório na política externa. Além do presidente e do partido, os militares acabaram tornando-se gradualmente uma fonte vital de input nas políticas doméstica e externa, devido aos desafios securitários domésticos. Ademais, também contribuíam para a conformação da política externa os grupos de pressões existentes, os quais, como já citado, eram originários da relação entre grupos internos (UNITA) e seus aliados externos.

Dessa maneira, em concordância com as considerações de Milner (1997, p. 12, tradução nossa), "a política doméstica raramente é puramente hierárquica, com um tomador de decisão unitário, mesmo em sistemas não democráticos ${ }^{8 "}$ como o caso de Angola ${ }^{9}$. O apoio dos militares profissionais, das oligarquias de terras, dos grandes empresários e/ou dos partidos políticos é usualmente necessário mesmo para que os ditadores permaneçam no poder e implementem suas políticas. Esses grupos, assim, podem comumente exercer o poder de veto sobre as propostas do executivo e, em outras circunstâncias, como na escolha da agenda, podem dividir poder com o executivo. Para além do fato de que Angola se tornou um importante campo de batalha da Guerra Fria, em que tanto os Estados Unidos quanto a antiga União Soviética usaram laços desenvolvidos com a UNITA e MPLA durante a guerra anticolonial para intervir na guerra civil, Malaquias (2000) acrescenta que a política externa de Angola deve ser compreendida principalmente em relação à busca do MPLA por estratégias para o fortalecimento de seu governo desde a sua conquista ao poder. O colapso de setores-chave como saúde, educação, transporte e comunicações enfraqueceu o Estado de direito. Dado esse contexto doméstico, caracterizado pela guerra e outras formas de decadência, a política externa foi vista como uma ferramenta importante para ajudar o novo regime a criar o ambiente de segurança necessário para resolver sua miríade de problemas domésticos.

Diante dos desafios internos, o governo do MPLA recalibrava regularmente as relações internacionais de Angola como uma ferramenta para envolver aliados externos que poderiam

\footnotetext{
8 "Domestics politics is rarely a pure hierarchy with a unitary decision maker even in nondemocratic systems. the support of the professional military the landed oligarchy, big business, and or a political party is usually necessary for even dictator to remain in power and implement their policie. these groups can often exercise veto power over the executive's proposals and in other ways such as setting the agenda may share power with the executive".

${ }^{9}$ Segundo Dahl (2005 apud MATOS, 2017), a poliarquia é um parâmetro para mensurar a democracia. Sendo assim, é possível analisar se um Estado é democrático por meio de 8 condições: 1. Liberdade de formar e aderir a organizações; 2. Liberdade de expressão; 3. Direito de voto; 4 . Elegibilidade para cargos públicos; 5 . Direito de líderes políticos disputarem apoio; 5 a. Direito de líderes políticos disputarem votos; 6. Fontes alternativas de informação; 7. Eleições livres e idôneas; 8. Instituições para fazer com que as políticas governamentais dependam de eleições e de outras manifestações de preferência. Considerando 0 caso de Angola, esta apresenta desempenhos menores em todas essas categorias.
} 
ajudá-lo a superar esses desafios (MALAQUIAS, 2000). Destarte, de acordo com Silva (2015, p.148) no que tange ao nível regional, a política externa angolana foi fundamentada na tentativa de consolidar o Estado e o regime. O amparo à South West Africa People's Organization ${ }^{10}$ (SWAPO) e ao African National Congress ${ }^{11}$ (ANC) foi fundamental como instrumento de barganha frente aos principais apoiadores da UNITA.

Desde a independência, a política externa do governo angolano foi elaborada principalmente como uma resposta a várias pressões internas e internacionais que ameaçavam sua estabilidade. Para tal, Angola procurou, acima de tudo, criar um ambiente regional favorável. Segundo Alves (2013 apud SILVA, 2015), o MPLA buscou superar as suas questões de ordem interna, mantendo alianças com os países socialistas e não alinhados entre 1975 e 1991.

À vista disso, examinar a condução da política externa do MPLA durante a Guerra Fria perpassa diretamente sobre o conflito interno enfrentado. As divergências de interesses e a luta pelo controle do Estado foram questões pertinentes que delinearam as relações exteriores tanto do MPLA quanto da UNITA que apesar de ser considerado na época um partido ilegítimo reivindicava o controle do Estado e também contava com apoio externo.

\section{O PROCESSO DE INTERNACIONALIZAÇÃO ECONÔMICA E AS MUDANÇAS NAS PROJEÇÕES DA POLÍTICA EXTERNA ANGOLANA ENTRE 1992 E 2002}

O fim da era bipolar (1991), que resultou na dissolução da URSS e no avanço do neoliberalismo como principal estrutura política econômica do sistema internacional, influenciou diretamente muitos países do então chamado Terceiro Mundo, culminando em um processo de mudanças em seus regimes políticos e econômicos. Não é, pois, surpreendente que tal alteração tenha constituído um desafio radical à ordem instituída. O impacto desta mudança estrutural do sistema internacional e da liberalização sentiu-se em quase todo o continente africano.

Em Angola não foi diferente. O término da Guerra Fria e a expansão do neoliberalismo afetaram diretamente o país. O MPLA mudou sua postura perante o sistema internacional, passando de uma economia centralizada para uma economia de mercado ${ }^{12}$. Para Lima (2000, p.265) "a abertura econômica representou uma nova realidade das políticas domésticas e internacionais dos países periféricos. Esses países experimentaram processos de reforma institucional abrangente tanto no campo econômico quanto político".

\footnotetext{
10 Oficialmente conhecido por, SWAPO - Partido da Namíbia foi o movimento que lançou uma guerra para conseguir a independência da Namíbia (anteriormente chamada Sudoeste Africano).

11 É um movimento e partido político sul-africano. Foi fundado em 1912, na cidade de Bloemfontein, com a proposta de advocar os direitos da população negra do país.

12 Contudo, mesmo com essa alteração, Angola passou a enfrentar a pior fase da guerra civil desde sua independência. Nesse cenário, teve-se o apoio das operações de paz da ONU juntamente com o auxílio de Portugal, Rússia e Estados Unidos durante aproximadamente 10 anos (1989-2002), a fim de restabelecer a paz e a reconstrução estatal, assim conter a guerra civil, travada principalmente entre o MPLA e a UNITA. (THOVA, 2015).
} 
Essa transição na estrutura econômica de Angola fez com que os EUA mudassem sua posição no que diz respeito ao seu apoio na região como também fez com que o país estreitasse suas relações com os estadunidenses. A presença das indústrias petrolíferas norte-americanas proporcionava grande atividade empresarial naquela região africana. Durante essa época, Angola era o terceiro maior parceiro comercial dos EUA na África Austral. A partir de 1993, os EUA reconheceram o então governo de Angola, cujo presidente era José Eduardo dos Santos (MPLA).

As mudanças de interesses dos grupos angolanos no governo não somente foram influenciadas pela conjuntura que se firmava no sistema internacional, como também a nível nacional. A forte intervenção estatal na economia não surtia efeitos positivos desde a independência. Houve a necessidade de busca por políticas que atraíssem investimentos estrangeiros e reduzissem o papel do Estado.

De acordo com Lima (2000), a globalização no sentido amplo da internacionalização da economia e de diversos fenômenos sociais fomenta a superação da fronteira internolexterno e consequentemente a internacionalização da agenda doméstica. A integração à economia internacional e a abertura econômica contribuem para a politização da política externa em vista dos impactos distributivos internos da maior participação do comércio internacional, uma vez que uma economia aberta há ganhos e perdas diferenciados, frutos de decisões e negociações internacionais.

No caso de Angola, sua inserção na economia mundial foi delineada pela dependência da exploração de recursos naturais como o petróleo, com a atuação direta de multinacionais estadunidenses. A responsabilidade do governo e das empresas para com a sociedade foi muitas vezes negligenciada, o que resultou em que a maior parte dos habitantes não desfrute das riquezas geradas por estas atividades econômicas. Como resultado, a pobreza e a desigualdade social se tornaram a realidade do país. (GUEDES; SIMÃO, 2017).

A primeira mudança estrutural iniciou-se em dezembro de 1990 quando o Congresso do partido renunciou formalmente ao marxismo-leninismo e consolidou, em maio de 1991, uma reforma constitucional. A reforma abriu caminho para uma legislação eleitoral que amparou as eleições de setembro de 1992. No mesmo mês, uma nova revisão constitucional foi aprovada estabelecendo mecanismos de descentralização governamental. Consequentemente, os desafios redundaram em crescentes esforços de fortalecimento da capacidade estatal, o que habilitou o país para estabilizar-se internamente e possibilitou políticas mais ousadas em nível regional e continental. (SILVA, 2015).

Hodges (2004) salienta que as reformas políticas com apoio externo em Angola, somadas a essas mudanças no plano internacional e regional, constituíram uma estrutura favorável para a implementação das negociações entre o governo e a UNITA, que ocorreram em Portugal nos anos de 1990 e 1991. Pela primeira vez, as partes rivais angolanas estavam sendo conduzidas à assinatura de um acordo de paz, assumindo o compromisso de cumprí-lo; as tratativas em 
Portugal culminaram na assinatura dos Acordos de Bicesse ${ }^{13}$. Estes estabeleciam o cessar-fogo entre o MPLA e a UNITA; o desmantelamento das tropas da UNITA; a formação de novas forças armadas do governo; a desmobilização das tropas excedentes; a restauração da administração governamental das áreas dominadas pela UNITA; um parlamento multipartidário e eleições presidenciais. (HODGES, 2004 apud PERCISI, ano p.85).

Vale ressaltar que a partir deste acordo foi realizada a primeira eleição no país em 29 de setembro de 1992. O MPLA foi eleito com 49,57\% dos votos ${ }^{14} \mathrm{e}$, em segundo lugar, ficou a UNITA, que insatisfeita com o resultado acusou as eleições de serem fraudulentas, o que agravou ainda mais a crise em Angola. Dessa maneira desencadeou-se a remilitarização da sociedade e a volta do conflito, numa luta armada de reclamação do poder absoluto entre os dois opositores. "Após negociações inconclusivas e o descumprimento das cláusulas dos acordos, o conflito cessou somente em $2002^{15}$, com a morte do líder da UNITA, Jonas Savimbi, pelas Forças Armadas Angolanas" (MATOS, 2017, p. 68).

Mesmo com as alterações na Constituição, segundo Matos (2017) a existência de leis e de suas garantias constitucionais, na prática, são meramente ornamentais. Há uma falta de proteção de direitos políticos, liberdades civis e liberdade de imprensa, que torna Angola um país não livre. Ademais, não há uma interação satisfatória entre o governo MPLA e a população angolana, o que contribui para o aprofundamento da desigualdade social, como também um obstáculo à consolidação da democracia. Além das eleições, José Eduardo dos Santos, anunciava, em 1992, mudanças na estrutura econômica, tendo como pano de fundo a relação com o mercado petrolífero, principal produto de exportação e fonte de riqueza do país (SOARES, 2011).

Essa transição foi patrocinada pelas instituições internacionais como o Fundo Monetário Internacional e o Banco Mundial, que pressionavam por essas mudanças, aplicando uma série de medidas vinculadas à imposição de uma disciplina macroeconômica e microeconômica que se destinam a apoiar a liberalização de mercado.

Umas das cláusulas obrigava o país a entrar em um acordo nacional e cessar a guerra civil. Para tal, as Operações de Paz da ONU tiveram o papel de conter o conflito, a fim de ajustar - Estado angolano, aos moldes estabelecidos na década de 90, quais sejam: liberalização econômica, "transparência política" e estabilização nacional. (PARIS, 2004 p.10). Concomitantemente como afirmado por Keohane e Milner (1996):

\footnotetext{
${ }^{13}$ O Acordo de Paz de Bicesse, assinado entre José Eduardo dos Santos (líder do MPLA) e Jonas Savimbi (líder da UNITA), almejava iniciar um período de transição política do regime de partido único para 0 multipartidarismo. "Entretanto, esse acordo foi curto e descuidado, não incluiu atores não armados (atores "morais", políticos, cívicos, etc.) no processo. Não foram introduzidas regras políticas para a transição, e a própria Organizações das Nações Unidas (ONU) ficou à margem na negociação" (MESSIANT, 2004 apud MATOS, 2017, p. 61).

${ }^{14}$ Disponível em: <http://africanelections.tripod.com/ao.html\#1992_Presidential_Election> Acesso em: 27 jun. 2018

${ }^{15}$ Em 2002 foi assinado o Acordo de Luena, entre o MPLA e a UNITA, que tinha principal premissa o término da guerra civil angolana além de propor a desmilitarização das forças da UNITA.
} 
Durante a década de 1990, , intensas pressões foram exercidas pelos países industrializados avançados em países em desenvolvimento para abrir suas economias. Instituições Financeiras Internacionais, tais como o Fundo Monetário Internacional e o Banco Mundial, intensificaram suas ênfases nessa condicionalidade. Ao longo de uma variedade de dimensões, os regulamentos econômicos nacionais de países em desenvolvimento foram moldados por Estados poderosos. Como sempre na economia mundial, o poder importa ${ }^{16}$. (KEOHANE; MILNER, 1996 p. 24, tradução nossa)

Ademais, ao longo do período em que vigorou a ordem mundial bipolar, Angola perdeu sua base de sustentação com o apoio da URSS e seu modelo econômico centralmente planificado fadou-se ao fracasso. Os fatores internos também contribuíram para esta mudança. A instabilidade militar e o elevado grau de dependência da economia com relação a um único produto de exportação - o petróleo - deixava o país extremamente vulnerável aos choques de preço do produto, apontando para a necessidade da diversificação econômica nacional (SOARES, 2011).

O governo necessitava atrair investidores para o país o que o levou, diante das pressões, a se apoiar nas instituições financeiras internacionais para tal objetivo. Reforçando essa mesma ideia, Paris (2004, p.65) afirma que ocorreu "um apoio oficial a reformas econômicas orientadas para o mercado". Este apoio do governo angolano aos princípios democráticos de mercado se refletiu nas muitas pressões que enfrentou no início dos anos 90. A única perspectiva do MPLA de obter investimento externo e ajuda financeira para Angola foi negociar uma aproximação com os Estados Unidos e as instituições financeiras internacionais, que, por sua vez, exigiram reformas orientadas para o mercado.

A adoção pelo governo do modelo de economia voltada para o mercado e o fim subsequente do modelo de economia planificada ocorreu em condições extremamente delicadas; tanto em termos políticos quanto econômicos. Politicamente, com a queda do muro de Berlim e com o fim do bloco socialista, o governo perdeu um dos principais aliados na empreitada que consistia na edificação de um estado socialista. Como a economia angolana é fortemente dependente da exportação de diamantes e, sobretudo, de petróleo, a queda dos preços destes produtos no mercado internacional levou à drástica redução das reservas cambiais e ao declínio da capacidade de importar. Nas palavras de Keohane e Milner (1996);

A abertura econômica e a redução de barreiras comerciais levará à concentração geográfica de indústrias e especialização. Novos fluxos de capital em controle com os fluxos de mercadorias criarão diferentes tipos de choques em uma economia .Isso sugere por exemplo que as crises políticas experimentadas pelos países devem diferir dependendo do tipo de interferência internacional ${ }^{17}$. (KEOHANE; MILNER, 1996, p.15, tradução nossa)

\footnotetext{
${ }^{16}$ During the 1990s, for instance, intense political pressure was exerted by advanced industrialized countries on developing countries to open their economies. International financial institutions, such as the International Monetary Fund and the World Bank, intensified their emphasis on conditionality. Along a variety of dimensions, the national economic regulations of developing countries were called into question by powerful states. As always in the world economy, power mattered.

${ }^{17}$ A reduction in trade barriers. will lead to geographical concentration of industries and to export specialization. As noted above, greater capital flows in contrast to goods flows Will create different types of shocks to an economy. This suggests, for example, that the political crises experienced by countries should differ depending on their type of international exposure.
} 
Em Angola esse processo de internacionalização econômica aumentou o seu grau de dependência externa. No campo, o êxodo rural fragilizou cada vez mais a produção agropecuária, levando à falta de produtos básicos para a economia. Por sua vez, os produtos manufaturados, antes produzidos localmente, passaram a constituir-se em elementos de significativa presença na pauta das importações. O parque industrial passou por um longo período de recessão, com o agravamento do conflito militar. De acordo com Fortunato (2001, p.18) "somente a indústria extrativa, tinha sido responsável pela sustentação macroeconômica do país, representando ao longo da década aproximadamente $50 \%$ do Produto Interno Bruto, e mais de $80 \%$ do total das exportações". Em função da conjuntura econômica, política e militar que o país vivia, grande parte dos recursos financeiros são usados para os órgãos de Defesa e Segurança, em detrimento de setores vitais da economia, adiando todas as perspectivas de crescimento econômico do país.

É dentro deste ambiente que o governo anunciou o Programa de Saneamento Econômico e Financeiro (SEF). Dada a urgente necessidade endrentada pelo governo, assentado na escassez de recursos cambiais, e buscando apoio do meio ocidental em função da degradante situação militar, o SEF representou, em tese, uma "Carta de Intenções" dirigida ao FMl e ao Banco Mundial. Usando uma política de austeridade financeira, com o conflito desestabilizando a execução de programas econômicos, o SEF surgiu como a tábua de salvação e mais no limiar dos anos 1990, representou o definidor da política econômica do país. (FORTUNATO, 2001).

Nesse contexto de enorme complexidade de fatores interagindo entre si, de ordem interna e externa, consubstanciando em elementos econômicos, político, social e militar, é que se formalizou a execução da política econômica de Angola. Apesar dos diversos programas de estabilização "a taxa de crescimento do Produto Interno Bruto (PIB), caiu de 8\% ao ano em 1994, para 5\% em 1998” (FORTUNATO, 2001, p. 21).

Consequentemente, como apontado por Keohane e Milner (1996) a internacionalização tem efeitos profundos sobre a política interna, embora as formas que esses efeitos tomam variam entre os países devido a condições institucionais e político-econômicas diferentes. Os efeitos da internacionalização requerem, portanto, análise do seu impacto tanto nas preferências políticas e quanto nas restrições e oportunidades enfrentadas pelos governos.

Como evidenciado, as mudanças políticas e econômicas de Angola no pós-Guerra Fria tiveram impactos negativos. A internacionalização da economia foi acompanhada por déficits de crescimento e aumento da dependência externa. Ademais, o Estado angolano não possuía ainda instituições políticas sólidas capazes de fomentar estratégias que minimizassem os efeitos da liberalização econômica.

Angola, durante muito tempo viu o seu espaço e capacidade de ação reduzidos no sistema internacional por causa do conflito armado que viveu. Com a transição da guerra para a paz, o Governo angolano sentiu a necessidade de redefinir a sua política externa, bem como os objetivos a alcançar no domínio externo. "A defesa da independência e a integridade territorial, deixaram de ser os objetivos principais da política externa angolana, dando lugar a novos objetivos, como a reconstrução nacional e a promoção da imagem de Angola no sistema internacional". (SIMIÃO, 
2014, p.7). Nesse sentido, "reformulava-se, a política externa angolana com base nos princípios de respeito mútuo pela soberania e integridade territorial, reciprocidade de vantagem e não ingerências nos assuntos internos de cada país". (SIMIÃO, 2015, p.38).

Assim, como as mudanças políticas econômicas as modificações na política externa foram fundamentais para a reinserção de Angola no sistema internacional, houve esforços da diplomacia angolana em participar de conferências multilaterais a fim de promover a paz e realizar acordos comerciais principalmente na África Central e Austral, além de negociações diplomáticas, no âmbito da ONU, da CPLP (Comunidade dos Países de Língua Oficial Portuguesa), da SADC (Comunidade para desenvolvimento da África Austral), da UA (União Africana), entre outros.

Para além das instabilidades enfrentadas na época e a busca por uma ampliação nas suas relações exteriores, o governo angolano adotou também uma política externa orientada para contenção da UNITA. Esta tarefa não foi fácil porque a UNITA era um movimento que detinha poder, embora não institucional e internacionalmente reconhecido, mas de fato "ocupava território, coordenava órgãos políticos e administrativos, tinha um aparelho militar bem constituído, controlava estruturas produtivas e tinha representações diplomáticas”. (SIMIÃO, 2015, p.40).

Entre 1992 a 2002 a estratégia da política externa angolana consistiu em angariar apoio internacional para combater a ala militarista da UNITA, conseguindo levar as Nações Unidas a introduzirem uma série de sanções contra a mesma, nomeadamente a proibição de aquisição de equipamento militar e produtos petrolíferos, o bloqueio de viagens ao exterior do país para os seus membros e a proibição da exportação direta ou indireta de diamantes ilegalmente extraídos em Angola. Apesar do Conselho de Segurança das Nações Unidas implementar essas sanções contra a UNITA, a verdade é que elas continuavam a ser violadas.

Mesmo com algumas reformas políticas introduzidas, o presidente continuou adquirindo um papel crescente quase exclusivo na definição de política externa. Além do Ministério de Relações Exteriores enfrentar grandes dificuldades com uma burocracia mal treinada e pouco efetiva, os militares acabaram angariando grande respeitabilidade na política externa como ocorria durante a Guerra Fria. Sua credibilidade em negociações regionais levou a soldados-diplomatas adquirirem posições de embaixadores em locais importantes como em Nova lorque e na África do Sul (SILVA, 2015).

Para Silva (2015), a política externa de Angola pós-Guerra Fria tem se focado em situações que se vinculam diretamente aos problemas internos do país, relacionados à reestruturação do Estado. A sua participação nas guerras da República Democrática do Congo, a aliança com a Namíbia e a penetração no território da Zâmbia (para suprimir forças da UNITA) são indicadores que parecem sustentar esta percepção. Ademais, a parceria com a China e os EUA tem espelhado essa postura de utilizar a diplomacia de forma pragmática como facilitadora do processo de construção do Estado, atualmente baseado no alto fluxo de comércio de commodities e em investimentos em infraestrutura. 
A dependência econômica dos recursos naturais e a destruição de outros setores econômicos como a pesca e produção de café com a guerra denotavam a demanda de desenvolvimento de outros setores da economia nacional. Na esfera da legitimidade, as dificuldades derivadas da guerra civil, aliadas à escassez de recursos humanos, levaram a grandes problemas burocráticos. Embora houvesse investimentos significativos na capacidade coercitiva e aumento no rendimento de recursos naturais, o Estado teve dificuldades em expandir a sua presença pelo território e desempenhar tarefas básicas. O provimento de serviços públicos como saúde, educação, transporte e comunicação foi igualmente prejudicado com os anos de guerra e com o processo de liberalização econômica, (SILVA, 2015).

Milner e Keohane (1996, p.14, tradução nossa) observam que "compreender os efeitos da internacionalização exige, portanto, a análise de seu impacto tanto nas preferências políticas e incentivos em geral, quanto nas reações políticas dos grupos socioeconômicos aos seus efeitos e na forma como são mediadas pelas instituições domésticas ${ }^{18 " . ~ L o g o, ~ a ~ f o r m a ~ c o m o ~ o s ~ g r u p o s ~}$ domésticos frente ao governo angolano lidaram com o processo de abertura econômica não foram satisfatórias. Se por um lado a guerra provocou uma destruição dos setores produtivos em larga escala, por outro, a situação econômica agravou-se com a condução de políticas econômicas inadequadas.

A abertura econômica de fato contribuiu ainda mais para a sua vulnerabilidade perante as crises econômicas internacionais durante a década de 1990. Sendo assim, cabe salientar as observações de Keohane e Milner (1996), de que os interesses sobre os quais as coligações políticas domésticas descamam serão cada vez mais moldadas pelas forças econômicas internacionais. A internacionalização significa, portanto, que choques no exterior gerarão crises políticas e muitas vezes farão com que se reformulem as políticas domésticas, ou seja, afetando a autonomia dos governos. No caso angolano esses efeitos foram perceptíveis. A nova dinamização do sistema internacional e principalmente do mercado financeiro levou o país a colocar-se na órbita das instituições financeiras internacionais, resultando em uma reestruturação de sua economia, das suas instituições e consequentemente de sua política externa.

\section{CONSIDERAÇÕES FINAIS}

Este artigo buscou analisar a seguinte questão: quais foram as tendências e as mudanças da política externa angolana durante o período de 1975 a 2002 ano que marca o fim de seu conflito militar? A partir deste estudo foi possível compreender como a estrutura da política externa angolana foi resultado de múltiplas forças (tanto nacionais quanto estrangeiras) e do conflito entre os diversos atores que a construíram.

\footnotetext{
${ }^{18}$ Understanding the effects of internationalization thus requires analysis of its impact both on policy preferences and incentives more generally, and also on political reactions of socioeconomic groups to its effects and the way that political struggles over openness are mediated by domestic institutions.
} 
Logo após a sua configuração enquanto Estado soberano, Angola passou por sérias instabilidades internas, que contaram com a participação efetiva de agentes externos como os EUA e a URSS. Entre 1975 e 1991 a política externa do MPLA pautou-se em estratégias para a estabilização nacional. As divergências de interesses e a luta política com a UNITA foram determinantes nas ações de sua política externa .

O fim da Guerra Fria (1991) foi um marco para a nova fase do conflito civil e para a estrutura política e econômica angolana, que conforme foi apresentado, em termos políticos, suscitou na primeira mudança da constituição e a realização das primeiras eleições, enquanto em termos econômicos representou a passagem de uma economia centralizada, para uma ampla abertura econômica. Esse processo de abertura e consequentemente de internacionalização de sua economia, acarretou em mudanças da estratégia para sua política externa. Entre 1992 a 2002, os efeitos da internacionalização, os quais foram parcialmente negativos, fizeram com que o governo angolano projeta-se sua política externa voltada para o Ocidente na busca por apoio (tanto financeiro, quanto político) para reconstrução estatal.

Sendo assim, a forma como se desenvolveu a condução da política externa angolana de 1975 a 2002, "evidencia a interpenetração entre os âmbitos doméstico e internacional” (PUTNAM, 1988, p.460, tradução nossa ${ }^{19}$ ). A nível nacional, os grupos domésticos envolvidos na luta política almejaram alcançar seus interesses. Já a nível internacional, o governo angolano buscou conter as pressões domésticas, enquanto tentou minimizar as consequências adversas das mudanças no sistema internacional.

* Recebido em: 12 de dezembro de 2018 Aprovado em: 13 de julho de 2019

\section{REFERÊNCIAS}

CORTINHAS, Juliano. Associação de variáveis sistêmicas e domésticas na análise das decisões de política externa. Relações Internacionais em Revista, Curitiba, n. 6, 2006 p. 69-101.

FRANCISCO, Alberto Andrade Carvalho. A política externa de Angola durante a Guerra Fria (1975-1992). 2013. Dissertação (Mestrado), Universidade de Brasília. Programa de Pós Graduação em Relações Internacionais, Brasília.

FRIEDEN, Jeffry; ROGOWSKI, Ronald. The Impact of the International Economy on National Policies: An Analytical Overview. In: KEOHANE, Robert; MILNER, Helen V. Internationalization and domestic politics, New York, Cambridge University, 1996, Cap. 2, p.25-48.

FORTUNATO, Jaime. Análise da dependência externa e da inflação na economia angolana na década de 90. 2001. Monografia (Conclusão do curso). Universidade Federal de Santa Catarina. Departamento de Ciências Econômicas. Florianópolis.

${ }^{19}$ The most portentous development in the fields of comparative politics and international relations is the recognition among practitioners of the entanglements between the two. 
JOVETA, José. Política Externa de Angola de 1992 aos dias atuais. Caxambu, 33ํㅡㄹ Encontro Anual da ANPOCS, 2009. Disponível em: < https://www.anpocs.com/index.php/papers-33encontro/gt-28/gt19-24/1977-jovetajose-politica/file> Acesso em: 15 jun. 2018

KEOHANE, Robert O.; MILNER, Helen V. Internationalization and domestic politics: A Introduction. In: KEOHANE, Robert O.; MILNER, Helen V. Internationalization and domestic politics, New York: Cambridge University, 1996, Cap.1, p. 3-25.

LIMA, Maria Regina Soares de. Instituições Democráticas e Política Exterior. Rio de Janeiro: Contexto Internacional, v.22, n.2, julholdezembro 2000, p.265-303.

MAIA, Tatiana A intervenção das Organizações das Nações Unidas em Angola (1988-1999). 2006. Dissertação (Mestrado) Universidade Federal do Rio Grande do Sul. Mestrado em Relações Internacionais- Instituto de Filosofia e Ciências Humanas. Porto Alegre.

MALAQUIAS, Assis. Angola's Foreign Policy: Pragmatic Recalibrations. The South African Institute of International Affairs (SAllA), Johannesburg, n. 84, 2011, p.4-19.

MALAQUIAS, Assis. Angola's Foreign Policy Since Independence: The Search for Domestic Security. African Security Review, v. 9, n. 3, 2000, p.34-46.

MATOS, Pedro. "Nunca antes na história deste país". a cooperação brasileira (2003-2010) com África do sul, Nigéria, Angola e Cabo Verde. 2017. Tese (Doutorado) Pontifícia Universidade Católica de Minas Gerais. Programa de Pós-Graduação em Relações Internacionais. Belo Horizonte.

MILNER, Helen V. Interests, institutions and information: domestic politics and international relations. New Jersey, Princeton University, 1997.

PARIS, Roland. At War's End Building Peace After Civil Conflict . Cambridge University, 2004.

PERSICI, Rossana Sarmento Guerra e paz em Angola: um estudo sobre o papel da ONU e das grandes potências. 2010. Dissertação (Mestrado) Pontifícia Universidade Católica de Minas Gerais. Programa de Pós-Graduação em Relações Internacionais. Belo Horizonte.

PUTNAM, Robert. Diplomacy and domestic politics: the logic of two-level games. International Organization, v. 42, n. 3, 1988, p. 427-460.

ROQUE, Paula. Angola's Façade Democracy, Journal of Democracy, Baltimore, v. 20, n. 4, 2009, p. 137-150.

SILVA, Castellano Igor da. Política externa regional de Angola: mudanças frente à ordem sistêmica (1975-2010). Austral: Revista Brasileira de Estratégia e Relações Internacionais, v.4, n.7, Jan./Jun. 2015, p.139-172.

SOARES, Ricardo lliberal Peacebulding In Angola. J. of Modern African Studies, v. 49, n. 2, 2011, p. 287-314.

SIMIÃO, Isaac. Modelo de inserção de Angola no sistema internacional. Dissertação (Mestrado) Universidade de Évora. Mestrado em Relações Internacionais e Estudos Europeus. Évora, 2014.

THOVA, Daniel. A Política Externa de Angola na África Austral (1975-1992). Dissertação (Mestrado) Universidade de Évora. Mestrado em Relações Internacionais e Estudos Europeus. Évora, 2015. 